\title{
Energy and Economy: Recognizing High-Energy Modernity as a Historical Period
}

\author{
Thomas Love \\ Linfield College \\ Cindy Isenhour \\ University of Maine
}

Follow this and additional works at: https://digitalcommons.linfield.edu/soanfac_pubs

Part of the Anthropology Commons, Energy Policy Commons, Environmental Policy Commons, Environmental Studies Commons, History of Science, Technology, and Medicine Commons, and the Oil, Gas, and Energy Commons

\section{DigitalCommons@Linfield Citation}

Love, Thomas and Isenhour, Cindy, "Energy and Economy: Recognizing High-Energy Modernity as a Historical Period" (2016). Faculty Publications. Accepted Version. Submission 7.

https://digitalcommons.linfield.edu/soanfac_pubs/7

This Accepted Version is protected by copyright and/or related rights. It is brought to you for free via open access, courtesy of DigitalCommons@Linfield, with permission from the rights-holder(s). Your use of this Accepted Version must comply with the Terms of Use for material posted in DigitalCommons@Linfield, or with other stated terms (such as a Creative Commons license) indicated in the record and/or on the work itself. For more information, or if you have questions about permitted uses, please contact digitalcommons@linfield.edu. 


\title{
Energy and economy: Recognizing high-energy modernity as a historical period
}

\author{
Thomas Love ${ }^{1} \&$ Cindy Isenhour ${ }^{2}$
}

Economic Anthropology, Vol. 3, Issue 1, pp. 6-16; Online ISSN: 2330-4847 9

\begin{abstract}
This introduction to Economic Anthropology's special issue on "Energy and Economy" argues that we might find inspiration for a much more engaged and public anthropology in an unlikely place - 19th century evolutionist thought. In addition to studying the particularities of energy transitions, which anthropology does so well, a more engaged anthropology might also broaden its temporal horizons to consider the nature of the future "stage" into which humanity is hurtling in an era of resource depletion and climate change. Net energy (EROEI), or the energy "surplus" on which we build and maintain our complex societal arrangements, is a key tool for anthropologists' as we bring our trademark cross-cultural, ethnographically grounded knowledge and perspectives to bear in examining the complex interplay of material infrastructures, energy flows, social organization, and culture. We are now mindful of the always already cultural nature of such circuitry and interactions - in ways obviously unavailable to our nineteenth-century forebears. And yet even as our energy futures are neither predetermined nor inevitable, neither are they as unfettered by material constraints as many have come to think. A robust anthropology of energy informed by awareness of the energetic basis of the historically specific moment in which we find ourselves seems poised to help us get beyond the developmentalist ideas of Morgan and Tylor and to overcome a seeming inability to think comprehensively about the human predicament in simultaneously general and particular terms. We have a chance in the space now opening to get beyond the antinomiesmaterialist - mentalist, infrastructure - superstructure, agency — structure, objective — subjective, and so on-that dominated much of twentieth-century anthropology.
\end{abstract}

Keywords: Net Energy; Culture Change; Infrastructure; Future; Public Anthropology

Renewed public interest in energy issues and a spate of recent work in an emerging anthropology of energy (e.g., Boyer 2014b; Strauss et al. 2013; Tyfield and Urry 2014) portend both a growing space in which to conceptualize what a now fragmented anthropology might offer a globalized world potentially on the brink of unprecedented powerdown and a quite unexpected return to some of the central issues around which our field first formed.

In the last year, the price of oil has dropped by nearly half (fromUS\$110 to aboutUS\$65 per barrel), taking most observers by surprise and plunging national economies and global commodity and financial markets into volatile, largely uncharted terrain. Recent growth in U.S. oil production has led many to declare "energy independence," yet the fracked shale oil that enabled growth is perhaps best seen as the "retirement party" for U.S. oil production (Berman 2015). Even more notable than some phantom return to growth, concerns about fossil fuels are now openly circulating at all levels of human societies. The leaders of the G7, for example, recently agreed to phase out fossil fuels by the end of the century -85 years from now. Yet these leaders' agreement may be meaningless if resource depletion, better or cheaper sources of

1 Department of Sociology/Anthropology, Linfield College, McMinnville, OR 97128, USA

2 Department of Anthropology, University of Maine, Orono, ME 04469, USA 
energy, or climate change lead to reduced use of fossil fuels long before the end of the century.

Such dramatic shifts again draw our attention to the tight connections between global financial flows, geopolitics, and energy (see Sager and Smith-Nonini, this volume). These events also elucidate a key set of linkages that can help us to understand both the irreducibly political nature of the challenges now presenting themselves (Mitchell 2013; Boyer 2014a) and the outlines of paths toward possible post-carbon futures (cf. Block 1990). The larger drivers of climate adaptation and declining net energy (Hall et al. 2009) that will undergird humanity's eventual, inevitable exit from the fossil fuel era constitute existential threats that now bring these complex linkages to the foreground, demanding our careful attention.

Coupled with such intertwined energetic, economic, and political processes is growing anxiety about widespread denial and political paralysis in the face of wider crises upon us. We already find ourselves in a curiously prolonged, late modern hiatus between convincing narratives about the energy basis of our civilization. This discursive break provides a space and an invitation to think through larger frames about the manifold connections between energy and economy.

The scale and breadth of these converging challenges have created a space in which old and new narratives are jostling for position. Business as usual seems untenable even as "the beginning of something new" (Graeber 2011) is still hard to discern. The "Anthropocene" meme is rapidly gaining currency as a way to conceptualize this seemingly unprecedented period in human, indeed, Earth, history. As Bruno Latour (2014) recently reminded anthropologists, with global climate change upon us, even natural scientists are taking human agency into systematic account, however reluctantly. He wondered aloud whether anthropologists, many of whom have long and especially recently defined the field against the "natural" sciences, are ready to engage such big interdisciplinary conversations about humanity's past and potential futures (cf. Boyer 2014a:316 ff.).

Contributors to this volume exploring connections between economic and energy anthropology recognize and argue that our utter dependence on the continued flow of energy through society is always already both cultural - understood in terms often distant from modern "scientific" understanding of such processes - and deeply intertwined with political and economic processes. How might we best proceed to explore these complex relationships between energy and economy?

In dialogue with Boyer (2014a), we argue here that to more fully and publicly engage these pressing matters as anthropologists (and citizens) is not only to step up our interdisciplinary commitments but also, to a surprising degree, to reengage the frameworks and concerns of an "earlier" anthropology (Wolf 1983:ix) that was deeply concerned with broad patterns of social change. Anthropology certainly has forbears for such wider engagements. Animated by the postWorld War II promise of unlimited atomic energy, Leslie White-whom we credit with launching the anthropological study of energy - drew on twentieth-century developments in physics and the natural sciences to illuminate the energic basis of Morgan's (and Marx's) earlier insight into the importance of material (technological) bases for such broad social change (cf. Boyer 2014a:310). 
With their linear developmentalist and ethnocentric models having long been jettisoned, however, why invoke Morgan or White, let alone Marx, to introduce this collection of contemporary anthropological papers on "Energy and Economy"? Writing in the dramatic sweep of nineteenth-century scientific and technological advances unfolding all around them, it is understandable how our field's founders believed that scientific progress was inevitable, accelerating, and seemingly stage like. Later, beguiled by the spectacular secular achievements of the twentieth century, it is similarly understandable how White imagined that modern "technology" had in some way fundamentally freed humanity from the material and energy constraints to which humans have been (and always will be) subjected.

Today, as we encounter planetary limits to growth and recognize anew the material and energetic bases of modern society, a fresh encounter with the ghosts of these founding nineteenth-century theorists beckons. Stepping back to examine the broad contours of our field in the current crisis, however, we ask, Are we committing a similar error - by unthinkingly assuming that solutions can be found in ongoing technological progress and uncritically confiding in the "inevitability of global newness" (Tsing 2000; cf. Nader 2004)?

We invoke "Morgan" as a synecdoche to argue that, in the context of today's converging, epochal challenges, at the end of the fossil fuel "stage" of human history, it is crucial to think, once again, about broadly contextualizing our place in human history. We must move toward a public anthropology that encourages people to break with reality as given - to see modernity as a historical phase, in order to make room for the development of plausible post-carbon narratives that make understandable that which is already unfolding around us.

In doing so, however, we must steer clear of metaphors that obscure as much as they reveal. The Anthropocene meme now gaining traction is one such example, for though it highlights the unprecedented historical phase we are now entering, it also masks the structured inequalities that have produced it. We're not all equally collectively responsible for present conditions, and some people benefit from current arrangements at the expense of most others. We can be sure that the coming energy transition will play out very unevenly, both among regions and among social classes.

Yet, in attending to the diversity and emergent nature of human experience in the fluid, kaleidoscopic nature of late modernity, anthropology has moved away from examining the broader sweep of human history and the deep connections humans have with Earth's life support system, which is, finally, finite.

So mighty is the power harnessed by our existing social arrangements that we barely grasp all that has been enabled by the one-time gift of ancient solar energy. Like Morgan and his contemporaries, we can hardly imagine an end to modernity, however aware of its vast inequalities and vulnerabilities we may now be. Yet anthropologists, with deep historical and cross-cultural perspective, are uniquely situated to question such claims of inevitability and to synthesize broad historical trends and social change - all while recognizing the heterogeneity of people's lived experience. As the articles in this volume demonstrate, we are also well positioned to examine the cultural contexts and drivers of our present era, for example, from oil reserve 
estimations (C. Wood) and electricity pricing (Özden-Schilling) to the complex relationships among debt, energy, and power (Sagers, Firat).

We know that anthropology coalesced during a time of rapid global change as an intellectual space for inquiry into the secular causes of human similarities and differences, cutting its teeth examining drivers of change in human history. Nineteenth-century intellectuals strove to account in naturalistic terms for both the achievements of Western civilizations and the factors that had inhibited cultural others from such achievement - the yearning for material and societal advancement presumed to be common to all humankind. In this sense, all the nineteenthcentury social scientists - even Durkheim - were "developmentalists" of one sort or another (Fox 2000). However flawed, they tried to understand the massive social, economic, and political changes under way all around them by putting all of humanity's experience in the same intellectual and analytical (evolutionary) frame - thereby launching a "science of human history."

Laden with now antiquated, colonialist notions that equated economic prowess with moral superiority, by the later twentieth-century developmentalist schemes of all flavors were largely abandoned in anthropology (though less so in economics, e.g., modernization theory). Two world wars, various genocides, and a host of social ills further challenged that progressivist narrative. Yet it is far from an odd anachronistic return to nineteenth-century thinking for us to acknowledge similarities between the framings of Marx, Morgan, and, later, White and the contemporary urge - spurred by increased perception and knowledge of energetic and ecological limits - to think anew about humans in the movement of history and about the collective future of humanity. Standing on their imperfect shoulders, combining their insights about general patterns in social change with our more contemporary attention to hybridity, power, and positionality, energy anthropology has the potential to make major, public contributions to our understanding of the nature of life in and dealing with the transition out of high-energy modernity. The insights of "Morgan" enable us to think about the fossil fuel era as a stage in human history and that it is the post-carbon transition, not continued growth, that is now inevitable. In the process, we must be careful neither to overdetermine nor to underdetermine the nature of the hard choices now upon us, reminding ourselves and wider audiences of their fundamentally political and cultural nature.

Such an approach compels us to explore anew questions about the place of energy in enabling human agency and driving basic trends affecting broader social patterns. Twin questions emerge from this perspective that beg for anthropological insight. First, what future possibilities are foreclosed or enabled by emerging constraints imposed by net energy decline, climate change, and the need for a significant energy transition or powerdown? In short, keeping in mind the relative autonomy of the state and significant geopolitical interests in the current system (cf. Mitchell 2013), what "stage" might come next? Second, how are people variously situated in sociopolitical space, in economic structures, and across cultures experiencing our continued dependence on carbon-intensive fuels and making sense (or not!) of the historically unprecedented energy transition now upon us? Both themes hinge fundamentally on perennial questions about the nature and limits of human agency. We briefly explore these two themes in the next two sections before concluding by previewing the collected articles and outlining how the contributions to this special volume engage these questions. 


\section{The crucial role of the net energy concept in regard to "what comes next?"}

Despite the mid-twentieth-century horrors of nuclear weaponry and an emerging Cold War, Leslie White reflected modern societies' general optimism at the dawn of the atomic age (cf. Boyer 2014a:311-312). Comfortable as many of us have since become with the privileges of life under late modernity, however, the tables now seem quite abruptly turned. It is increasingly clear that the material benefits to which we in the developed world have become so accustomed over the last two centuries rest fundamentally on harnessing ever more prodigious supplies of high-quality energy. This was, of course, White's insight: that economic development and form are, to some irreducible degree, a function of energy capture. Technological innovation and wizardry, like fracking, don't matter much if there are no high-quality energy resources to find.

There is some minimal energy return on energy invested (EROEI), some minimal threshold of energy gain that any society must achieve to maintain the economic and societal complexity it considers adequate (Murphy and Hall 2011). EROEI serves as a unitless metric for the amount of "surplus" energy over basic subsistence that any human society has to run everything else they do and value, harkening back to Steward's culture core concept as well as White's energy harnessed per capita concept. Net energy is also closely related to the evolution and maintenance of social complexity (Tainter 2006). For our enormously complex modern industrial societies, that minimum EROEI ratio appears to be something between 5 and 8 units of energy returned for every 1 unit invested (Hall et al. 2009). If we can use history as a guide for the future, Tainter (1988) has argued that when the marginal costs of maintaining complexity become uneconomical, economizing "collapse" ensues.

As larger, more easily accessed deposits of oil, coal, and natural gas dwindle, we are learning that the "peak oil" problem is essentially an economic problem-a problem of committing more and more capital and physical resources (ever more energy, finally) to finding sufficient energy just to stay in place. Though new technology has been credited with ushering in our current shale oil boom, adding to U.S. and world oil supply, these technologies are not in fact new; rather, we are committing more debt-financed capital investment to accomplish this production increase. In short, the current, lower-EROEI oil boom has come at much greater economic and environmental costs. The financialization of declining net energy reveals the tight connections between energy and economy (see later), which have yet to be adequately theorized (see Sager, Smith-Nonini, and C. Wood, this volume). As this "Red Queen" effect becomes more apparent, economic recovery will be ever more ephemeral and confined to ever smaller portions of society.

As human population and consumption inexorably draw closer to Earth's natural limits, we find ourselves in the beginning of the end of the fossil fuel era that characterizes and makes the global industrial economy possible (Love 2008). Although students of this predicament differ on the rate, nature, and effects of this energy regime transition, it is increasingly clear that the modernity we and most readers of this essay know is utterly dependent on Earth's one-time gift of finite stores of fossil sunlight.

We also increasingly understand that the combustion of carbon-based fuels is polluting and changing the fundamental chemistry of our atmosphere and oceans, setting in motion shifts in Earth's core biophysical systems. Natural scientists and economists tell us that the potential 
costs of such changes are significant and will compound the longer we wait to act (Stern 2006; Jakob et al. 2012;U.S. Council of Economic Advisors 2014). Together, resource depletion and climate change have the potential to significantly constrict economic activity. We face the prospect that without massive conversion to post-carbon fuels, continued progress (as we currently define it) cannot be sustained, let alone extended to the two-thirds of humanity yearning for modern levels of consumption and mobility.

As anthropologists, we can see how the modernist metanarrative of endless progress was enabled by the confident post-World War II prospect of seemingly endless technological development, itself predicated on the then high net energy of the world's giant oil fields. Having quickly come to think of this temporary state of affairs as normal, much of humanity has taken high-energy modernity for granted. Continuing technological achievement - especially our ultramobility, but also the digitized, electrified, hyperconnected scapes that most of humanity now inhabits, has blinded most of us to the energetic basis of our civilization. Even with various technological developments and promising gains in energy efficiency, the inescapable fact is that we are no less dependent on the continued flow of high-quality energy through our systems than were our forebears. In fact, we are far more dependent on affordable, high-quality energy than has been any civilization preceding us; about 80 percent of the primary commercial and noncommercial energy consumed by members of Organization for Economic Co-operation and Development (OECD) countries (86 percent in the United States) comes from fossil fuels. Yet, because of the "invisible" nature of energy and a culture that takes its provision for granted, many are surprised, if not terrified, to learn that fossil fuels are being rapidly depleted and are thus getting harder and more expensive (both economically and environmentally) to produce. There is much work to be done on energy mystification and energy fetishism in relation to energy flows and net energy decline.

Though the transition from the fossil fuel era is upon us, posing enormous challenges we barely yet grasp, it is not at all clear that alternative energy sources are capable of providing the net energy gain (e.g., Prieto and Hall 2013) to which we had so quickly become accustomed over the past half-century. Nor is it clear whether they can be built out fast enough, with current financial arrangements, enormous global debt, and the high upfront costs of renewable energy technologies, to compensate for the declining quantity and quality of fossil fuel resources.

As increasing numbers of anthropologists from diverse corners of the field bring these energy trends and drivers into consideration, it is our fervent hope that we will take the insights developed in the articles in this volume of Economic Anthropology to wider publics who can benefit from the uniquely wide-angled yet grounded insights we can bring to the table. But before we can educate wider publics, we must ourselves understand - deeply-how and the degree to which we have come to be so hugely dependent on finite fossil fuels.

So even though Morgan's or his contemporaries' stage-like progressivism could not imagine or allow that net energy underlay techno-economic change, and that a decline in EROEI might therefore undermine the ever-upward advance of societal complexity, their periodizing of history prefigures and even informs our late-modern concerns. With Morgan (and White, and Marx) looking on, we ask both how we've come to be so dependent on fossil fuels and what the next "stage" after high-energy modernity might be. But how should we-or, better, how can 
we - think about societal and economic transitions and perhaps even the end of fossil fuelenabled growth, a prospect that for most living in advanced postindustrial societies (and the majority of humanity aspiring to develop their economies) is literally unthinkable? As late modern humanity hurtles forward on clearly unsustainable foundations, an anthropology that does not help wider publics put such existential concerns into perspective is not living up to its promise.

An emerging anthropology of energy promises to contribute in very public ways to helping wider publics imagine what sort of new economic as well as political, social, and cultural forms might develop around unprecedented, widespread, and already unfolding crises of energy and economy. An increasingly robust anthropology of energy - anchored in the multiple realities of decreasing net energy, heady global energy finance, and alternative energy markets explored at the Society for Economic Anthropology meetings in spring 2014-promises to return us to the very roots of our assumptions about the nature of change, technology, identity, and history. Social class and class conflict, the place of technology in social change, the nature of the economy and its relative social embeddedness - suddenly the concerns that preoccupied Morgan, Tylor, Marx, Spencer, and other nineteenth-century figures don't seem quite so clunky and oldfashioned. Indeed, dimming prospects for continuing business as usual invite our deepest intellectual engagement with the nature of and prospects for our civilization.

\section{What can we learn from the lived experience of energy transitions?}

Developing broad historical and cross-cultural perspectives on the energetic basis of modern as well as traditional societies is one fruitful way to talk with wider publics about the net energy situation now unfolding. Archaeologists have played a critical role in bringing into focus past human experience with energy transitions (e.g., Tainter 1988), though loss of complexity has heretofore been a local, not global, phenomenon. Anthropologists can certainly also contribute toward understanding cultural as well as other barriers to the political, economic, and technical transitions upon us.

But understanding these broad contours of our era is not enough. Although we see many people growing increasingly alarmed about long-term prospects, others are in blissful denial of the global overshoot predicament in which we are now finding ourselves (cf. Catton 1980). Consumed by the demands of everyday life, the practicalities of short-term challenges, and an array of structural barriers, even those most concerned about natural resource depletion and climate change fail to take action (Isenhour 2010a, 2010b).

Powerful interests, vested in the current energopolitical arrangements and feeding ideologies of continued material growth, can also help to explain inaction. These interests continue to shape dominant views of the challenges we face as well our conceptualizations of feasible solutions, as outlined by a number of scholars who have traced the interrelationships between political and economic influence (Oreskes and Conway 2010; McCright and Dunlap 2003; see Firat, Smith-Nonini, Cielo et al., Lord, and D. Wood, this volume).

Indeed, there is significant disagreement in many international contexts and at different scales pitting those who hold faith in the status quo and an inevitable sense of progress against those who see impending doom. Somewhere in the middle is the vast majority of humanity, 
whether in affluent core societies or in a periphery gripped by hopes for material abundance. As anthropologists and citizens, we can help to understand these diverse perspectives and to develop more public discussions of energy. Recognizing and helping people to understand our common plight is the beginning of wise action and may well hinge on our collective ability to fashion new metaphors that make sense of the fundamentally inchoate nature of the present moment.

But as net energy awareness spreads, it is spurring both apprehension about collapse and more sharply focused hope for the prospects for transition from high-energy modernity. Anthropologists' closer examination of how people's lives are actually tied to energy flows is needed. We know that humans can live satisfactory, meaningful lives on a fraction of the energy budget of modern societies (see Bucciferro, this volume). What might people's responses to power-down be (see Rupp, this volume), and what possibilities for and experiments in transition can we discern in the noisy tumult of late modern societies (see Acheson and Acheson, and Campbell et al., this volume; cf. Lockyer and Veteto 2015)?

So how do these larger trends and processes actually play out on the ground in the energy circuitry enabling people's everyday lives? Practice theory points to the durable dispositions that seem to hinder rapid change in energy use (Wilhite 2013), tied as they often are to the already sunk costs of infrastructural development (see Johnson, this volume). Culturally situated expectations powerfully affect risk assessment, from the estimation of the nature and scale of low-EROEI oil deposits (C. Wood, this volume) to the prices charged to electricity users (ÖzdenSchilling, this volume).

Yet despite significant differences in risk perception, the financial implications of declining net energy are enormous and may finally be determinative. Because the extension of credit hinges on the ability of debtors to repay loans made on the prospect of future growth, less future net energy means that in the absence of alternatives, credit will dry up - a dagger pointed right to the heart of the capitalist growth economy. As Sager and Smith-Nonini (this volume) note, the United States and other industrial states have been able to continue wildly spending without consequence, with the United States occupying a privileged position because only it can issue more dollars, racking up debt that must be financed. Part of this is the United States's role as not only lender but also consumer of last resort, soaking up excess production during periods of downturn. However, at some point, sooner or later, some country will break with the current, overextended Bretton Woods II arrangement and start selling oil and other major commodities in currencies other than U.S. dollars, dealing a potentially crippling blow to U.S. hegemony as the dollar loses its reserve currency status.

Delayed engagement and transition may bring other potential consequences, for example, the decline of the middle class and the normativity of middle-class identity. Although in the United States, we use gender, race, religion, and other codes to talk about the forbidden reality of class (Ortner 2006), awareness of social class is likely to come roaring back into social analysis and everyday discourse in the case of collective power-down, sudden if not unanticipated energy transitions (see Rupp, this volume), or shrinking economic growth. Faced with these prospects, we can be confident that people will revert to time-honored practices converting windfall profit or material wealth into social capital (cf. Bourdieu 1986). If only some citizens could afford increasingly scarce energy, the illusion of middle-class prosperity in the United States and other 
advanced countries would also surely dissipate.

Although we have argued that reengaging Morgan can be surprisingly insightful, many may argue that it is a renewed conversation with the ghost of Marx that really looms here. Because people are differentially positioned in social space and in their access to the means of production, the increasing rupture of contemporary social organization will surely play out in very different ways for different groups of people. Yet this variability does not preclude us from recognizing both broad historical trends and the patterns that script for such variability in experience and adaptive capacity.

Economic anthropologists have huge contributions to make to our understanding of these complex relations between energy and economy. Our methodological toolkit is extraordinarily well suited to capturing and describing the ways people make sense of, make decisions about, and are affected by the epochal transition between energy regimes that is already upon us. Drawing on both our deep historical and cross-cultural lenses and our unique ethnographic engagement with highly contextualized human experiences in a global system, we have the ability to bridge a greater understanding of the reality and dialectic of both structure and agency, the material and the ideal, the local and global, the universal and the particular.

\section{Organization and key themes of the collection}

This collection of essays brings a number of these important themes to light. While we've separated the articles into four primary sections, on production, infrastructures, communities, and transitions, there are several additional crosscutting themes. For example, a number of papers in this special volume address state making (Firat, Lord, Cielo et al., Sager, Smith-Nonini, Bucciferro), electricity (Rupp, Özden-Schilling, D. Wood, Lord), the effects of deregulated energy markets (Özden-Schilling, D. Wood), financialization (Sager, Smith-Nonini, Lord, C. Wood), distributed energy (D. Wood, Johnson), poverty alleviation through energy development (Cielo et al., Lord, Campbell et al., Acheson and Acheson), the "invisible" nature of contemporary energy (Rupp, Johnson, D. Wood), future making (Firat, C. Wood, Lord), and the important and arguably constitutive nature of energy information (C. Wood, Özden-Schilling).

We begin with "Energy, Economy, and Society"-four articles that share an interest in viewing these patterns through the lens of production. Drawing on ecology, economics, and archaeological research, Justin Bucciferro reminds us of the energetic basis of human civilization, providing a novel and robust model to reexamine precolonial population estimates. The following three articles engage the connections among resource extraction, monetary regimes, and economic power, but they do so from diverse yet complementary perspectives. Together they remind us that the flow of energy through human societies is a fundamentally economic act that is nevertheless always already cultural.

Drawing on seminal research in ecological economics and historical economic analysis, Jalel Sager illustrates the links among energy, finance, and global power by drawing parallels between the monetary dominance of the United Kingdom during the peak of coal mining in the nineteenth century; the United States during the petroleum boom of the twentieth century; and the growing influence of China during the twenty-first century, with the exploitation of Chinese coal mines. In all cases, productivity, global economic power, and monetary hegemony were 
linked to growth in the domestic (and colonial) energy supply. As such, energy resources are the "foundation for a favorable balance-of-trade position." For those nations with energy sources increasingly costly to extract, Sager suggests that fading competitiveness often translates into market fundamentalism as nations attempt to "leverage their power to produce market outcomes heavily tilted toward their own benefit . . obscur[ing] deep state involvement in the mechanics of market design and operation."

Taking an ethnographic approach to the links between energy production and economy, Caura Wood introduces us to the world of entrepreneurial energy corporations and the geological and economic formulas they employ in efforts to generate profit. She argues that oil and gas production is not just a function of infrastructure and state planning (see Firat and D. Wood, this volume) but is also dependent on speculative formulas for profit maximization. These formulas are much more than "mere agents of calculation" but are performative (see also ÖzdenSchilling, this volume), helping to constitute both current and future energy production. However, as Wood's ethnographic account makes clear, financial formulas don't always translate seamlessly into geological reality. The "tight oil" speculation she describes is linked less to new discoveries, technological advancement, or their associated shifts in supply and demand than to addressing problems with corporate and government illiquidity.

Sandy Smith-Nonini bridges materialist and idealist approaches as she explains the relationship between hydrocarbon extraction and contemporary economic forms. Echoing both Jalel Sager and Caura Wood, Smith-Nonini connects the rise of speculative energy finance and neoliberal ideologies to the peaking of U.S. domestic oil production in the early 1970s. This shift, she argues, allowed for ongoing capital accumulation while simultaneously disguising increased market, social, and environmental risks and exacerbating global and localized inequalities.

The second section, "Infrastructure, Movements, and Markets," examines the infrastructural undergirding of energy production, trade, and consumption. Drawn from three different perspectives, these articles from the United States, Turkey, and the United Kingdom remind us that although buried and invisible infrastructure may not be the most obvious place to start a study of energy and economy, both material and virtual infrastructures form the very foundation of our engagements with energy and help to shape economic and social form.

Canay Özden-Schilling's ethnography takes us deep inside an energy market intelligence company, outlining both the complexity and uncertainty of the data used for energy price forecasting and trading. She argues that, however imperfect, today's information is the virtual infrastructure of the deregulated U.S. energy market: "Deregulation rearranged, not the transmission equipment of the electric grid, but the information relationships around it." In this context, the burden to organize information was passed on to market actors who act on much more than the laws of supply and demand (see also C. Wood, this volume), including also a complex and imperfect market infrastructure built of information. Expertise is constructed in this social context that creates order in an inherently fluid and information-short space.

Bilge Firat continues our discussion of infrastructure with her analysis of Turkish investments in material networks of energy transport. In contemporary Europe, infrastructural 
developmentalism is being championed at a moment when economic, financial, and political integration seems less certain. Turkish leaders, eager to improve and secure the state's global position, are investing heavily in projects designed to situate Turkey in the center of AsiaEurope international energy flow and trade. Whereas some critique these massive investments as a "political dreamscape," others echo the founding principles of the European Union, based on an ideology of peaceful, codependent cooperation. Firat argues that superprojects like the TransAnatolian Pipeline not only make dreams of integration apparent but also highlight economic inequalities. These massive infrastructural projects "unfold in contradictory and nonlinear ways," involving “"dreamscapes' of territorial integration, energy hubs, and material power [that] turn into realities that integrate and develop, but in different and far less holistic ways than their architects had imagined."

Charlotte Johnson takes a historical approach to analyzing the relationships between energy infrastructures, social organization, and governance. Focusing on a post-World War II experiment intended to foster social democracy through socio-spatial organization, Johnson outlines how district heating in London's Churchill Gardens worked to reshape relations between the citizen, the market, and the state. By participating in district heating arrangements, citizens enter into unique social contracts, with both rights and responsibilities that construct shared assets and ordered space to manage the consumption of energy. Tracing societal developments into the present, Johnson encourages us to recognize the social contracts materialized through district heating infrastructure as "heterotopic spaces" that link sites of consumption and production through "sociotechnical relations" - a new angle on habitus in relation to energy flow.

Although ethnographic engagements with the lived experiences of diverse energy regimes and economic forms are found throughout the collection, the third section, "Communities of Energy," draws our attention more specifically to the relationships between energy, our concepts of community, and human experience.

Reminding us how invisible yet indispensable energy has become in our everyday lives, Stephanie Rupp examines a series of historical and recent blackouts in New York City. These disruptions, she argues, are not only technological but, given the tight integration and interdependence of social and technological systems, mark significant disruptions in social organization and behavior: "When the circuits of electricity are broken, currents of power in technical, social, economic, and political arenas are also disrupted." Rupp concludes with the recognition that although energy is a fundamental element in the constitution of our societies and cultures, the study of disruption provides a space for recognizing that, in its absence, "people are not bound by wired circuits whose tracks we are relegated to trace. When the circuits are broken, people find alternative ways to connect."

Cristina Cielo, Lisset Coba, and Ivette Vallejo also provide insight into the social implications and lived realities of energy and development policy. Ecuador's National Development Plan for Good Living (buen vivir) was designed by the progressive Correa regime to redistribute the profits of hydrocarbon extraction to local communities. Development projects like the City of the Millennium, constructed in the heart of the Ecuadorean Amazon, were heralded as a means to integrate and include the communities most affected by petroleum 
extraction in the national economy. However, Cielo, Coba, and Vallejo clearly demonstrate the contradictory nature of Ecuador's development agenda - a curious energopolitics that remains dependent on an extractive economy while creating new subjects of development that are utterly dependent on the state-institutionalized energy regime.

Ben Campbell, Jon Cloke, and Ed Brown observe a sense of urgency in the implementation of low-carbon energy transition programs intended to both reduce climate impact and enable economic development in communities of the Global South. Although these objectives are certainly laudable, the authors caution that the concept of "community" needs "critical reflection, disambiguation, and interrogation" to ensure that "positions of marginality and commonality in emerging social energy systems" are not glossed over. Drawing on examples from their research in Nicaragua and Nepal, the authors suggest a framework for understanding communities of interest in selective resistance to and appropriation of energy.

Our final section pays particular attention to "The Economy (and Politics) of Energy Transitions." Both cautionary and hopeful, the pieces collected here suggest that participation in and democratization of energy planning are clear steps in the right direction.

Austin Lord's analysis of Nepal's ambition to become a "hydropower nation" and associated investments in development suggest that the production of the hydropower future drives a co-evolutionary process in which territoriality, governance, and subjectivity are shaped by overlapping projects of future making. Lord's ambitious consideration of all aspects of Nepal's transition to hydropower focuses on the continuities and disjunctures between the political economy that supports rapid hydropower development and the lived realities of "project-affected persons." Lord finds that although many Nepalese welcome hydropower development, locating themselves within the hydro-imaginary as a means to assert their rights, there is an ongoing dissonance between the massive and rushed investments and continued risk and underdevelopment in these affected watersheds.

James Acheson and Ann Acheson's survey of Maine residents suggests that the majority of favorable perspectives on wind power are linked to benefits for the society as a whole, such as reduced pollution and dependency on foreign oil. Nonetheless, Acheson and Acheson observe significant barriers for the development of wind power in Maine. The authors frame the issue as a "collective action problem" in which widely recognized benefits to be gained from cooperation (reduced pollution) may be outweighed by individual costs (a windmill in my fishing territory). Communities often overcome these collective action problems by formulating rules to ensure cooperation. Acheson and Acheson suggest that the theoretical perspectives of rational choice and collective action problems give no clear indication of the future of offshore wind development in Maine. However, as the results of Acheson and Acheson's surveys suggest, the majority of coastal Maine residents are highly supportive of offshore wind and cite collective benefits as the source of their support. This suggests a willingness to cooperate that could pave the way for offshore wind development in a state with significant wind potential.

Davida Wood examines the traditionally nontransparent and highly technocratic realm of long-term power development planning. Working with civil society groups in South Africa and 
Thailand, Wood observed an exclusive form of electricity sector governance, heavily influenced by entrenched interests and resulting in a "culture of over-forecasting and inflexible planning." Coupled with concerns about the neoliberal commercialization of the energy sector, climate change, and affordable energy, this exclusivity has led to increasing demands among civil society to decentralize and democratize power development planning. Outlining a series of civil society interventions aimed at securing access to both information for modeling and demand forecasting (see also C. Wood, Özden-Schilling, this volume),Wood argues that multistakeholder engagement can result in a transformative decentralizing process, a reconsideration of the technical assumptions that underlie demand forecasts and supplies, and the potential for distributed energy, reminding us that energy flows are never socially, politically, or culturally neutral.

\section{Conclusion}

In examining the complex interplay of material infrastructures, energy flows, social organization, and culture, we are mindful of the always already cultural nature of such circuitry and interactions - in ways obviously unavailable to our nineteenth-century forebears. A robust anthropology of energy informed by awareness of the net energy basis for the historically specific moment in which we find ourselves seems poised to help us get beyond the developmentalist ideas that incubated Morgan's and Tylor's launching of anthropology and to overcome a seeming inability or unwillingness to think comprehensively about the human predicament in simultaneously general and particular terms. We have a chance in the space now opening to get beyond the antinomies - materialist-mentalist, infrastructure-superstructure, agency-structure, objective-subjective, and so on-that dominated much of twentieth-century anthropology. Recent encouraging developments in energy anthropology in these respects include the development of practice theory in relation to energy flows (Wilhite 2015) and a Foucauldian-inspired concept of energopolitics (Boyer 2014a).

In sum, both sets of concerns animating this introduction-discerning the nature of the future "stage" into which we are hurtling and understanding clearly how people are experiencing and understanding this unprecedented energy transition - understood jointly, promise to stimulate a much more public and engaged anthropology. Even as our energy futures are neither predetermined nor inevitable, neither are they as unfettered by material constraints as many have come to think. Documenting the variety of ways people make their future in an era of declining net energy points to the great need for anthropologists to bring our trademark cross-cultural, ethnographically grounded knowledge and perspectives to bear on these matters of growing existential concern. In the process, such a more public anthropology promises to enrich the field as we learn to engage with and add value to public debate among diverse expert and general audiences.

\section{References}

Berman, Arthur

2015 The Artificial Shale Boom: Interview on BNN TV (Canada). April 11.

http://www.artberman.com/the-artificial-shale-boom-interview-on-bnn-tv-canada/, accessed June 24, 2015.

Block, Fred 
1990 Postindustrial Possibilities: A Critique of Economic Discourse. Berkeley: University of California Press.

Bourdieu, Pierre

1986 The Forms of Capital. In Handbook of Theory and Research for the Sociology of

Education. John G. Richardson, ed. Pp. 241-258. New York: Greenwood Press.

Boyer, Dominic

2014a Energopower: An Introduction. Anthropological Quarterly 87(2):309-334.

2014b Energopower and Biopower in Transition. Anthropological Quarterly 87(2).

Catton, William

1980 Overshoot: The Ecological Basis of Revolutionary Change. Urbana: University of Illinois Press.

Fox, Robin

2000[1877] Introduction. In Ancient Society. By Lewis Henry Morgan. New York: Transaction.

Graeber, David

2011 Debt: The First 5000 Years. New York: Melville House.

Hall, Charles A. S., Stephen Balogh, and David J. R. Murphy

2009 What Is the Minimum EROI a Sustainable Society Must Have? Energies 2:25-47.

Isenhour, Cindy

2010a On Conflicted Swedish Consumers, the Effort to "Stop Shopping" and Neoliberal

Environmental Governance. Journal of Consumer Behavior 9(6):454-469.

2010b Building Sustainable Societies: A Swedish Case Study on the Limits of Reflexive Modernization. American Ethnologist 37(3):511-525.

Jakob, M., G. Luderer, J. Steckel, M. Tavoni, and S. Monjon

2012 Time to Act Now? Assessing the Costs of Delaying Climate Measures and Benefits of

Early Action. Climatic Change 114(1):79-99.

Latour, Bruno

2014 Distinguished lecture presented at the annual meeting of the American Anthropological Association, Washington, DC.

Lockyer, Joshua, and James R. Veteto, eds.

2015 Environmental Anthropology: Engaging Ecotopia Bioregionalism, Permaculture, and Ecovillages. Brooklyn, NY: Berghahn Books.

Love, Thomas

2008 Anthropology and the Fossil Fuel Era. Anthropology Today 24(2):3-4.

McCright, Aaron M., and Riley E. Dunlap 
2003 Defeating Kyoto: The Conservative Movement's Impact on U.S. Climate Change Policy. Social Problems 50:348-373.

Mitchell, Timothy

2013 Carbon Democracy: Political Power in the Age of Oil. London: Verso.

Murphy, D. J., and Charles A. S. Hall

2011 Energy Return on Investment, Peak Oil, and the End of Economic Growth. Annals of the New York Academy of Science 1219:52-72.

Nader, Laura

2004 The Harder Path—Shifting Gears. Anthropological Quarterly 77(4):771-791.

Oreskes N., and E. Conway

2010 Merchants of Doubt: How a Handful of Scientists Obscured the Truth on Issues from

Tobacco Smoke to Global Warming. New York: Bloomsbury Press.

Ortner, Sherry

2006 Anthropology and Social Theory: Culture, Power, and the Acting Subject. Durham, NC:

Duke University Press.

Prieto, Pedro A., and Charles A. S. Hall

2013 Spain's Photovoltaic Revolution: The Energy Return on Investment. New York: Springer.

Stern, Nicholas

2006 Stern Review Report on the Economics of Climate Change. London: HM Treasury.

Strauss, Sarah, Stephanie Rupp, and Thomas Love, eds.

2013 Cultures of Energy: Power, Practices, Technologies. Walnut Creek, CA: Left Coast Press.

Tainter, Joseph

1988 The Collapse of Complex Societies. New York: Cambridge University Press.

2006 Social Complexity and Sustainability. Ecological Complexity 3:91-103.

Tsing, Anna

2000 The Global Situation. Cultural Anthropology 15(3):327-360.

Tyfield, David, and John Urry, eds.

2014 Energy and Society [Special issue]. Theory, Culture, and Society 31(5).

U.S. Council of Economic Advisors

2014 The Costs of Delaying Action to Stem Climate Change. Executive Office of the President of the United States.

https://www.whitehouse.gov/sites/default/files/docs/the_cost_of_delaying_action_to_stem_clima te_change.pdf, accessed March 11, 2014. 
Wilhite, Harold

2013 Energy Consumption as Cultural Practice: Implications for the Theory and Policy of Sustainable Energy Use. In Cultures of Energy: Power, Practices, Technologies. Sarah Strauss, Stephanie Rupp, and Thomas Love, eds. Pp. 60-72. Walnut Creek, CA: Left Coast Press. 2015 The Political Economy of a Low Carbon Transformation: Breaking the Habits of Expansive Capitalism. London: Routledge.

Wolf, Eric

1983 Europe and the People without History. Berkeley: University of California Press. 